\title{
Working
}

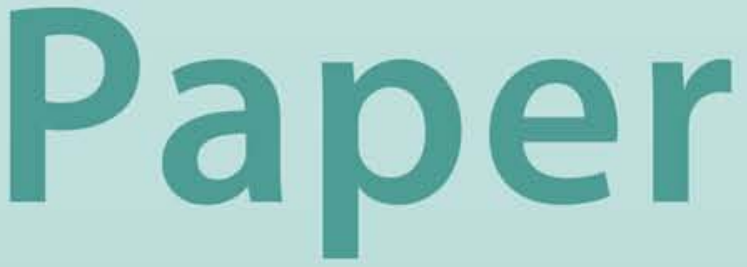


The END: A New Indicator of Financial and Nonfinancial Corporate Sector Vulnerability

Jorge A. Chan-Lau and Toni Gravelle 


\title{
IMF Working Paper
}

Monetary and Financial Systems Department

\section{The END: A New Indicator of Financial and Nonfinancial Corporate Sector Vulnerability}

\author{
Prepared by Jorge A. Chan-Lau and Toni Gravelle ${ }^{1}$ \\ Authorized for distribution by David Marston
}

December 2005

\begin{abstract}
This Working Paper should not be reported as representing the views of the IMF. The views expressed in this Working Paper are those of the author(s) and do not necessarily represent those of the IMF or IMF policy. Working Papers describe research in progress by the author(s) and are published to elicit comments and to further debate.

This paper describes a corporate sector vulnerability indicator, the expected number of defaults (END), based on the joint occurrence of defaults among a number of firms and/or institutions. The END indicator is general enough to assess systemic risk in the corporate and financial sectors, as well as systemic sovereign risk; and is also forward looking as it is constructed using information implied by financial securities prices. Using equity prices and balance-sheet data, we calculate the END to assess systemic risk in the corporate sector in Korea, Malaysia, and Thailand. We also discuss how the END systemic risk indicator overcomes some of the shortcomings of other vulnerability indicators.

JEL Classification Numbers: F30, G12, G14, G15

Keywords: Systemic Risk, Credit Risk, Corporate Vulnerability, Default Probability

Author(s) E-Mail Address:jchanlau@imf.org; tgravelle@bank-banque-canada.ca

\footnotetext{
${ }^{1}$ Senior Economist, International Monetary Fund, and Assistant Director, Financial Markets Department, Bank of Canada, respectively. Part of this work was done while Gravelle was an advisor in the Executive Director’s Office, International Monetary Fund. Ivan Guerra, Silvia Iorgova, and Peter Tran provided excellent research assistance. We thank Varapat Chensavasijai and seminar participants at the IMF for their comments and suggestions. Comments may be addressed to either of the authors. The views expressed here represent neither those of the Bank of Canada nor those of the International Monetary Fund.
} 


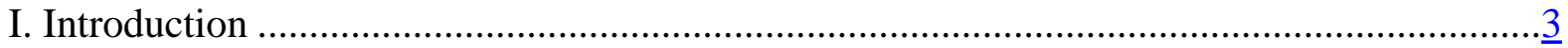

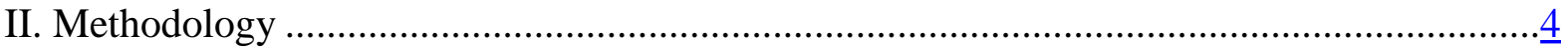

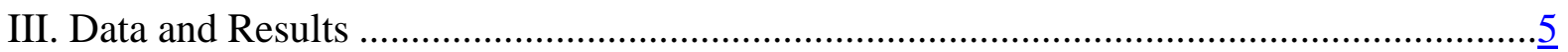

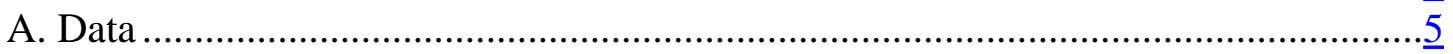

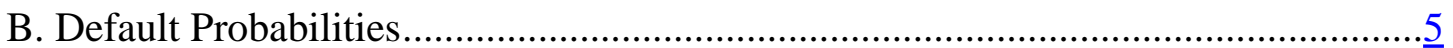

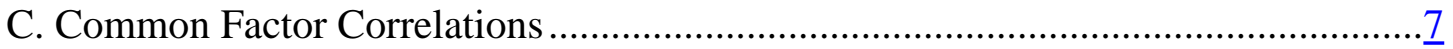

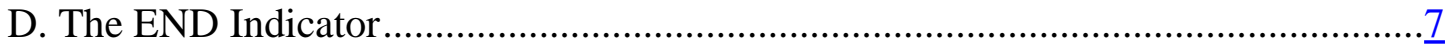

IV. Advantages of the END Measure over other Corporate Sector Vulnerability Measures ..... $\underline{9}$

A. Distance-to-Distress and Aggregation Issues ......................................................

B. Nth-to-Default Probabilities .........................................................................

C. Contingent Claims Approach .............................................................................

V. END: A Building Block for the IMF's Surveillance Work ............................................12

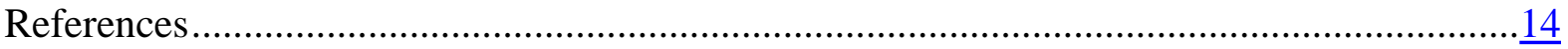

Tables

1. Korea, Malaysia, and Thailand: Corporate Default Probabilities, ..................................... $\underline{6}$

2. Korea, Malaysia, and Thailand: Principal Components Analysis .......................................

Figures

1. Korea, Malaysia, and Thailand: Mean Default Probability …............................................ $\underline{6}$

2. Korea, Malaysia, and Thailand: Expected Number of Defaults ..........................................

3. Korea: Expected Number of Defaults vs. Average Default Probability .............................10

4. Korea: Expected Number of Defaults vs. Probability of Observing N-Defaults..................11

5. Korea: Probability Distribution of N-Defaults ........................................................... 


\section{INTRODUCTION}

Costs associated with default of a single firm or country can be substantial, as witnessed by Enron's bankruptcy and the Argentina crisis in recent years. A single default, however, does not pose a major threat to financial system stability as long as it remains an isolated event. For example, the external debt default of Argentina was arguably anticipated by markets and did not raise concerns of a global debt crisis. In consequence, the impact on the borrowing costs of other emerging market countries was limited.

Financial and economic linkages, though, suggest that there may be instances in which an individual issuer's failure to meet its obligations may start a cascade of defaults. A dramatic example was the collapse of Long Term Capital Management, a large hedge fund, in 1998. Fears of a market-wide sell-off, and its potential disruptive effects on other financial institutions, prompted the New York Federal Reserve Bank to coordinate a private bailout of the hedge fund. Hence, for policymakers and investors seeking credit exposure, it is important to quantify the joint probability of default, or default contagion, among countries, corporations, and financial institutions.

In particular, much attention has been focused on systemic risk in the corporate sector following the financial crisis in East Asia in 1997-98. Indeed, one major source of vulnerability in the affected countries was the substantial exposure of the private corporate sector to adverse exchange rate movements arising from unhedged foreign-currencydenominated liabilities. Vulnerabilities in the corporate sector are transmitted economy-wide through the banking sector, since widespread corporate bankruptcies weaken banks' balance sheets and could prompt a banking crisis and the associated welfare losses due to a slowdown in economic activity, higher inflation, fiscal burdens, and bank and corporate restructuring.

There are an increasing number of studies developing indicators of individual corporate distress. In most instances, these indicators document the likelihood of corporate default or bankruptcy and are used by market participants in managing their portfolio exposures to various individual corporate entities. However, there has been a dearth of studies focused on measuring and predicting sectoral systemic risk.

We propose such an indicator of corporate sector vulnerability, the Expected Number of Defaults (END) - indicator. This indicator is based on economic theory and more importantly, uses the forward-looking information embedded in equity prices. Because equity prices are updated on a daily basis, implementation of the END indicator allows for real-time monitoring of potential distress conditions in the corporate sector. The usefulness of the END indicator is illustrated using corporate data from Korea, Malaysia, and Thailand. We also discuss its advantages vis-à-vis other corporate and banking sector vulnerability indicators recently put forward in the literature. The methodology used in this paper is explained in the next section. 


\section{Methodology}

This section provides a simple explanation of the methodology used in constructing the Expected Number of Defaults (END) indicator. ${ }^{2}$ The construction of the indicator for a given sample of firms follows a two step approach.

In the first step, a structural model of default risk widely used by financial practitioners is used to estimate each firm's individual default probability series. The model is a variation of that first proposed by Merton (1974). In his model, Merton builds on the observation that shareholders hold a call option on the asset value of the firm: when the asset value of the firm falls below the face value of its debt, the firm is insolvent and the shareholders' call option is out of the money. Hence, it is possible to use basic option pricing techniques to value the debt and equity issued by a firm. Furthermore, readily available balance-sheet information and equity prices can be used to infer the risk-neutral default probability and an associated measure, the distance-to-default of the firm, or a normalized measure of the gap between the firm's asset value and the nominal value of its liabilities.

While appealing, Merton's original model is unable to capture short-term default risk since continuity assumptions on the asset value stochastic process rule out the possibility of jumplike default events. However, the rapid demise of "fallen angels," that is, investment-grade corporations that went bankrupt in a matter of days, suggest that default events may be better characterized by jump processes than by continuous ones. The practitioner's model adopted in our approach corrects for this deficiency by introducing uncertain recovery rates in order to capture jump-like default events. The model also assumes that changes in asset values are stationary with a zero mean, which is consistent with the observation that firms attempt to maintain an optimal leverage ratio or, in the case of sovereign issuers, that countries attempt to keep a steady debt-to-GDP ratio. Despite introducing these assumptions, the model is still tractable and can be calibrated with the same data used to calibrate Merton's model: the issuer's balance-sheet data and equity prices.

The second step is to assess the probability that a subset of the firms analyzed default during a specified time horizon. During crisis periods, it seems reasonable to assume that a large number of defaults must be driven by a common negative shock affecting the corporate sector rather than by firm-specific factors. In other words, common vulnerability features across firms are exposed or "kick-in" during periods of economic or financial stress. This observation is captured well in the one-factor model of Vacisek (1987) in which the value of each firm (or each firm's assets) are differentially correlated with a common, time varying factor. The value of the firm also depends on a firm-specific shock.

Calibration of the one-factor Vacisek model requires first estimating the correlation of each firm's asset value with the common shock or factor. To accomplish this, it is necessary to specify the probability distributions of the common and idiosyncratic shocks. In this study, we assume that both shocks are distributed according to a standard normal distribution. Once

\footnotetext{
${ }^{2}$ Full technical details are given in a companion paper, Chan-Lau and Gravelle (2005a).
} 
the probability distributions are specified, it is possible to map the default probability estimated in the first step to a normalized asset value of the firm. Afterwards, correlations are estimated using principal components analysis, as we explained in detail next.

Recall that an underlying assumption of the structural model we estimate to calculate the END is that corporate valuations are driven by an unobserved common factor. Each firm's value over time is correlated to this common factor to varying degrees. In order to measure the individual correlation of each firm's estimated probability of default to this common factor we use a principal components analysis. This method assumes that a limited number of unobserved variables (or factors) explain the total variation of the larger set of variables. That is, the higher is the degree of co-movement across all individual firm default probability time series, the fewer the number of principal components (factors) needed to explain a large portion of the variance of the original series. In the case where the original variables are identical (perfectly collinear), the first principal component would explain 100 percent of the variation in the original series. Alternatively, if the series are orthogonal to one another (i.e., uncorrelated), it would take as many principal components as there are series to explain all the variance in the original series. In that case, no advantage would be gained by looking at common factors, as none exist.

Once the one-factor Vacisek model is calibrated, it is possible to obtain the probability distribution for the number of defaults. The END indicator is obtained by finding the expected number of defaults associated with the estimated default probability distribution. The END indicator has a number of advantages that would be evident in our analysis of systemic corporate risk in Korea, Malaysia, and Thailand below.

\section{DAta AND RESUlts}

\section{A. Data}

The methodology described in the previous section was used to estimate the END indicator for the corporate sector in Korea, Malaysia, and Thailand. Quarterly balance-sheet data and daily equity prices for nonfinancial corporates in these countries were collected from WorldScope for the period November 18, 1996 to December 31, 2003. The number of firms used to construct the indicators were 125 for Korea, 148 for Malaysia, and 79 for Thailand. For calibration purposes, it was assumed that quarterly balance sheet figures remained unchanged within each quarter. Total liabilities were set equal to short-term liabilities plus one-half of long-term liabilities, following standard industry practice.

\section{B. Default Probabilities}

Table 1 reports the summary statistics of the default probabilities for each country for three sample periods: the full sample period November 18, 1996 to December 31, 2003; a precrisis and crisis period from November 18, 1996 to December 31, 1999, and a post-crisis period from January 1, 2000 to December 31, 2003. 
Table 1. Korea, Malaysia, and Thailand: Corporate Default Probabilities, Summary Statistics

(In percent, unless otherwise indicated)

\begin{tabular}{|c|c|c|c|c|c|c|c|c|c|}
\hline & & South Korea & & & Malaysia & & & Thailand & \\
\hline From & 11/18/1996 & $11 / 18 / 1996$ & $1 / 1 / 2000$ & $11 / 18 / 1996$ & $11 / 18 / 1996$ & $1 / 1 / 2000$ & 11/18/1996 & $11 / 18 / 1996$ & $1 / 1 / 2000$ \\
\hline to & $12 / 31 / 2003$ & $12 / 31 / 1999$ & $12 / 31 / 2003$ & $12 / 31 / 2003$ & $12 / 31 / 1999$ & $12 / 31 / 2003$ & $12 / 31 / 2003$ & $12 / 31 / 1999$ & $12 / 31 / 2003$ \\
\hline Number of firms & 125 & 125 & 125 & 148 & 148 & 148 & 79 & 79 & 79 \\
\hline Mean & 12.3 & 11.5 & 12.9 & $\begin{array}{l}140 \\
8.2\end{array}$ & 7.5 & 8.7 & 22.8 & 21.7 & 23.6 \\
\hline Standard Deviation & 3.3 & 3.5 & 3.0 & $\begin{array}{l}0.2 \\
3.4\end{array}$ & 4.3 & 2.3 & 7.2 & 7.6 & $\begin{array}{c}2.00 \\
6.8\end{array}$ \\
\hline First Quartile & 10.1 & $\begin{array}{l}5.0 \\
7.1\end{array}$ & $\begin{array}{c}5.0 \\
10.7\end{array}$ & $\begin{array}{l}5.4 \\
6.4\end{array}$ & $\begin{array}{l}4.5 \\
2.3\end{array}$ & $\begin{array}{l}2.5 \\
6.5\end{array}$ & 15.7 & 14.2 & $\begin{array}{l}0.0 \\
16.8\end{array}$ \\
\hline Second Quartile & 13.0 & 13.1 & 12.7 & 8.5 & 9.3 & 8.1 & 22.5 & 21.6 & 22.8 \\
\hline Third Quartile & 15.1 & 14.3 & 15.9 & 11.2 & 11.3 & 10.7 & 29.6 & 28.3 & 30.4 \\
\hline Fourth Quartile & 17.3 & 16.2 & 17.3 & 12.8 & 12.2 & 12.8 & 34.1 & 33.8 & 34.1 \\
\hline
\end{tabular}

Source: WorldScope and authors' calculations.

There are no substantial differences across periods for the average default probability, standard deviation, and quantiles across firms for the three countries analyzed. Our sample, however, is affected by survivorship bias, since only those firms that survived the crisis are represented.

Figure 1. Korea, Malaysia, and Thailand: Mean Default Probability

(In percent)

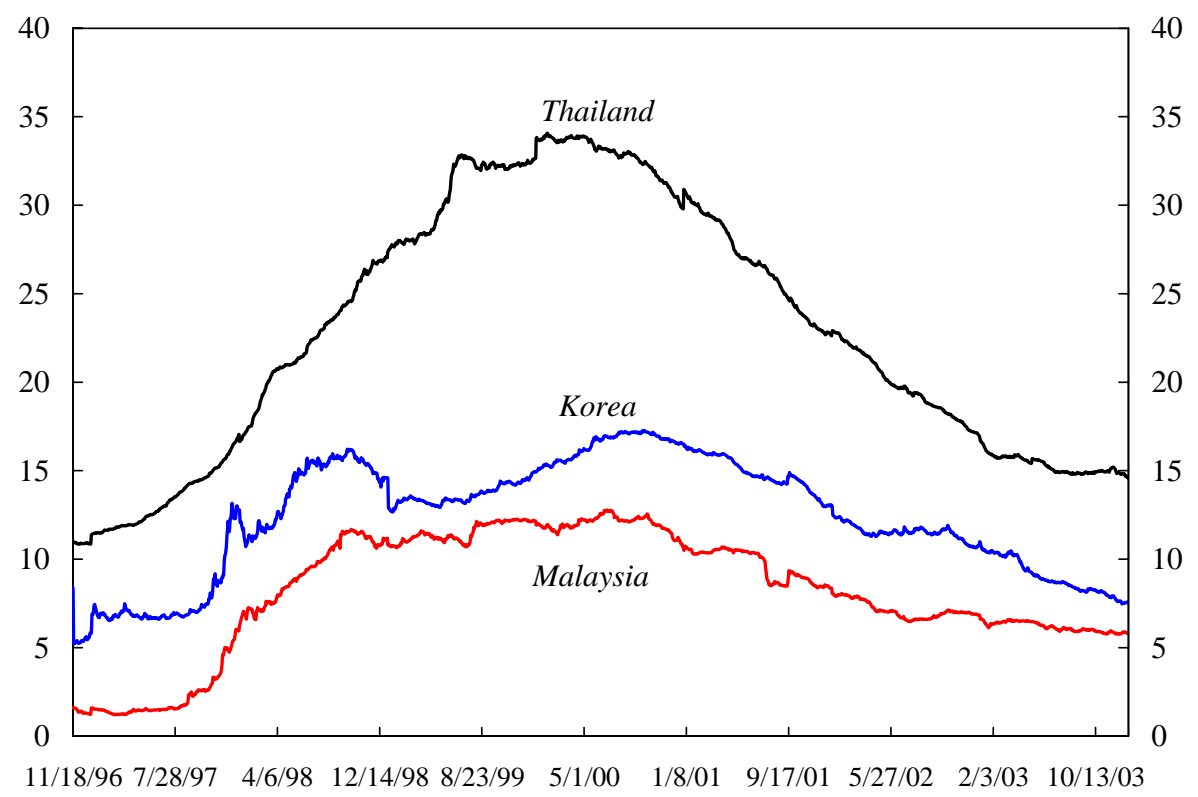

The information summarized in Table 1 is complemented by Figure 1, which shows how the mean default probability across firms evolved during the period analyzed. Though the countries experienced the crisis in 1997-98, the mean default probability peaked in mid-2000, 
two-and-a half-years after the onset of the crisis. Survivorship bias partly explains this dynamic pattern. The pattern, though, also suggests that in the aftermath of a crisis, reducing balance sheet vulnerability and restoring creditworthiness in the corporate sector following a crisis requires time.

\section{Common Factor Correlations}

After computing the default probabilities for each firm, we computed the amount of variation explained by the first two principal components of 125 firms in Korea, the 148 firms in Malaysia, and the 79 firms in Thailand during the sample period. The results presented in Table 2 reveal that the first principal component explains 68, 74, and 72 percent for Korean, Malaysian, and Thai firms respectively and that an additional 17, 16, and 16 percent, respectively, of the variation is explained by the second component. As such, the results reveal that one common factor explains a large proportion of the variation of each firm's default probability, and supports the underlying the common shock assumption for the END method. The principal components analysis also provides us with the individual firm's correlation (or loadings) with the unobserved common factors (which we assume to be the first principal component). The average correlation with the first principal component across firms for each country and the first to fourth quantiles are presented in Table 2.

Table 2. Korea, Malaysia, and Thailand: Principal Components Analysis

(In Percent)

\begin{tabular}{lccc}
\hline & South Korea & Malaysia & Thailand \\
\hline Explained variation & & & \\
$\quad$ First component & 67.8 & 74.2 & 72.6 \\
Second component & 17.4 & 16.2 & 16.1 \\
Correlations & & & \\
Average & 8 & 7 & 9 \\
First quantile & 6 & 3 & 8 \\
Second quantile & 8 & 7 & 11 \\
Third quantile & 10 & 10 & 45 \\
Fourth quantile & 27 & 23 & \\
\hline
\end{tabular}

Source: Authors' calculations.

The average correlation is relatively low and does not exceed 10 percent; about three-fourths of the firms have correlations below 10 percent. However, one-fourth the firms are highly sensitive to movements of the common factor.

\section{The END Indicator}

Once the default probability of each firm and its corresponding correlation with the first principal component are known, we can calculate the END indicator for each country using the one-factor Vacisek model. The results are illustrated in Figure 2. 
Figure 2. Korea, Malaysia, and Thailand: Expected Number of Defaults

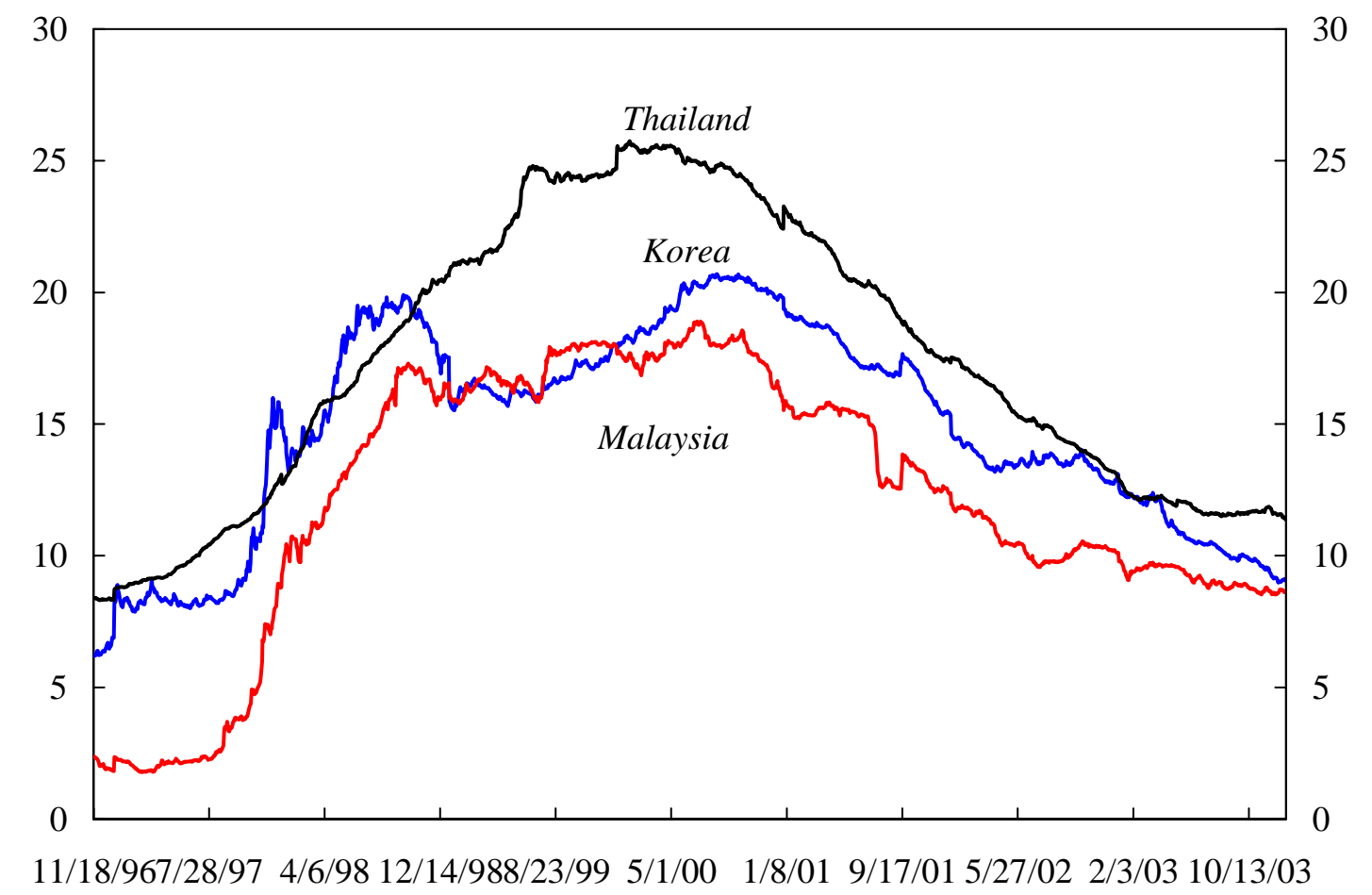

Recall that these results underestimate the true level of systemic risk since the sample is affected by survivorship bias. Nevertheless, the figure shows that the END indicator captures the increase in systemic risk during the Asian crisis in these three countries. Of interest is that although the END indicator rises in each country with the onset of Asia crisis as expected, it continues to rise well into 2000 for Malaysia and Thailand and to early 2001 for Korea, while only falling slowly thereafter to reach levels still above those observed before the Asian crisis.

The onset of the crisis exposed underlying vulnerabilities in the corporate sector of most Asian countries hit by the crisis. As discussed in Pomerleano (1999), Haksar and Kongsamut (2003), and Mako (2002), East Asian corporate sectors were characterized by high debt-toequity ratios and low interest coverage ratios even before the crisis. The sharp depreciation of the local currency increased further the debt burden of most firms and thus simply pushed large segments of each country's corporate sector into bankruptcy. The health of the corporate sector did not rebound as quickly as economic growth did in the region. In the case of Thailand, for example, various balance sheet measures of corporate health remained at critically low levels until well into 2001 and for some measures into 2002 (see Haksar and Kongsamut, 2003).

Strengthening the corporate sector took some time in the region (as opposed to the recapitalization of the banking sector). Specifically, given the breath of the corporate weakness, the corporate restructuring process that followed the crisis was a relatively drawn out affair, as reforms were often necessary to enable the restructuring process to advance (see 
Mako, 2002, for Korea and Haksar and Kongsamut, 2003, for Thailand). This means that indicators of corporate sector vulnerability would remain high, as shown in Figure 2, beyond the period of the crisis, when economic activity rebounded. We proceed to explain why the proposed vulnerability measure performs better than other structural model-based measures of corporate sector vulnerability.

\section{AdVAntages of THE END Measure OVER OTHER CORPORATE SECTOR VULNERABILITY MEASURES}

In this section, we explain why the END measure addresses a number of shortcomings of other proposed corporate sector vulnerability measures. While the analysis is illustrated using the results obtained for Korea, the analysis remains unchanged if the results corresponding to Malaysia and Thailand are used instead.

\section{A. Distance-to-Distress and Aggregation Issues}

The distance-to-distress (DD) measure, a normalized measure of the difference between a firm's asset value and its liabilities based on the work of Merton (1974), has become a widely used risk measure following the pioneering work of Moody's KMV. Work carried both inside and outside the Fund has shown that the distance-to-distress is effective for predicting ratings downgrades of financial and non-financial firms in mature and emerging

markets. ${ }^{3}$ Notwithstanding its merits, there are some disadvantages associated with individual measures of corporate DD. First, the measure cannot capture individual institutions' risks well over short time horizons because asset prices are not allowed to be discontinuous and the level of liabilities is assumed constant. In contrast, the END measure assumes that the level of liabilities is uncertain and hence can yield non-negligible default probabilities even over short time horizons.

Second, sectoral analysis based on DD relies on ad-hoc methods to aggregate individual firm's information that could lead to misleading estimates of systemic risk. For instance, in practical applications, sectoral probability of default (PD) or DD measures are sometimes constructed by aggregating firms' balance sheets and equity market values into one fictitious "megafirm." This aggregation problem could be better illustrated by taking the extreme example of a system comprising two equal sized firms, one fully financed with equity and the other fully financed by debt. The default risk of the megafirm, financed half by equity and half by debt, is not representative of the default risk in the system.

Similarly, measures of corporate vulnerability that are based on averages of individual corporations' DD or PD measures, as discussed in Tudela and Young (2003) for example, do not sufficiently account for changes in the degree of correlation across issuers. ${ }^{4}$ The use of

\footnotetext{
${ }^{3}$ For instance, see Hull, Predescu, and White (2004); Gropp, Vesala, and Vulpes (2005); and Chan-Lau, Jobert, and Kong (2004).

${ }^{4}$ See Chan-Lau (2004) for an application to emerging market issuers.
} 
weighted averages of individual DD measures, or equivalently the weighted average of default probabilities, may be justified when default correlations are low. For instance, in the case of Korea, where the average default correlation in the corporate sector is less than 0.10 , the average default probability, which is a proxy for average DD, traces well the evolution of the expected number of defaults, as illustrated in Figure 2. Notice, however, that the average default probability cannot capture swings in systemic risk during 1998-99.

Figure 3. Korea: Expected Number of Defaults vs. Average Default Probability

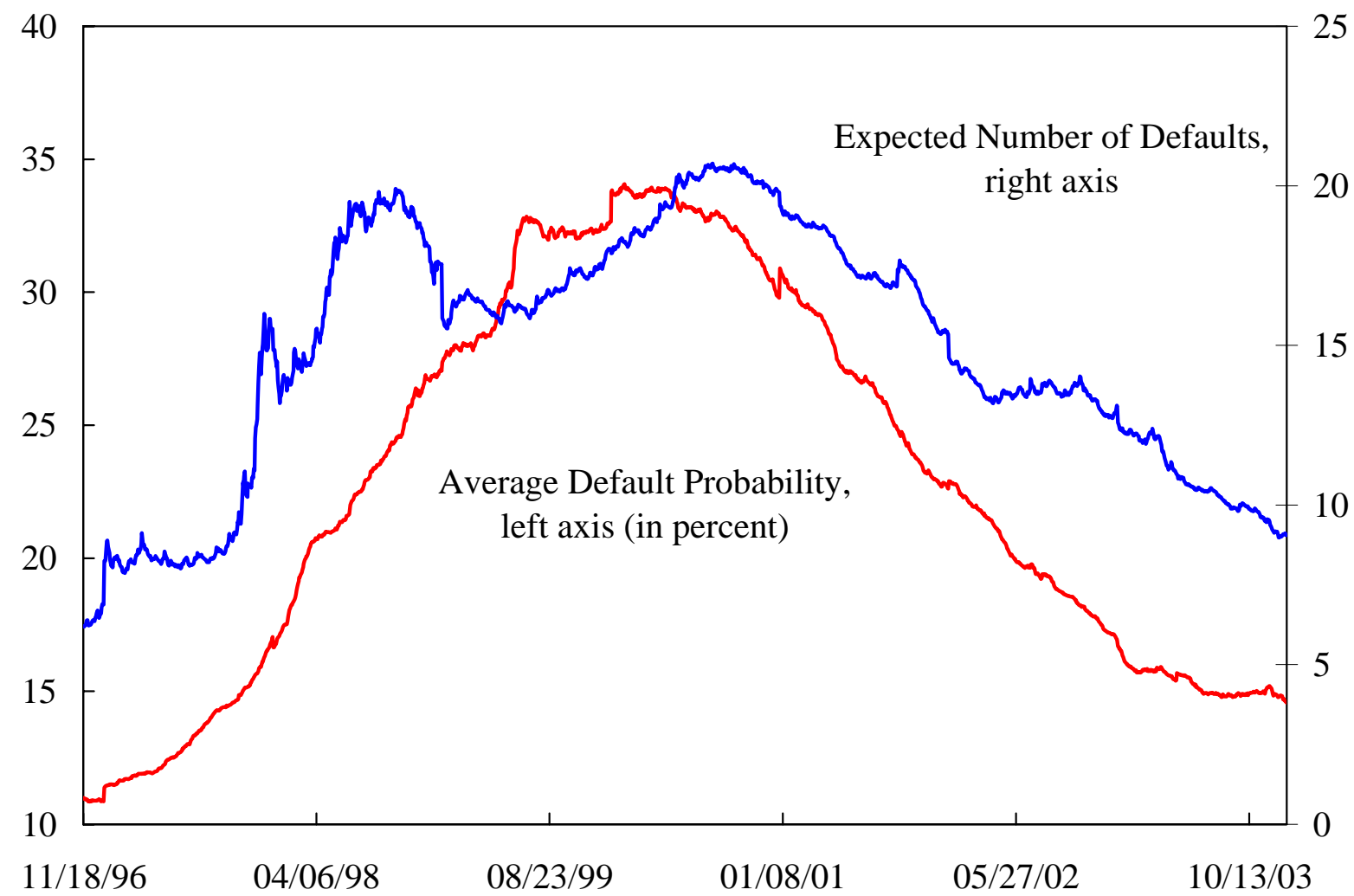

\section{B. Nth-to-Default Probabilities}

More recently, the First-to-Default (FTD) probability, or the probability of observing one default among a number of institutions, has been proposed as a measure of systemic risk for large and complex financial institutions (IMF, 2005). ${ }^{5}$ This measure is constructed using risk-neutral default probabilities implied from credit default swap spreads. The FTD probability addresses one of the shortcomings of the DD measures, namely, the possibility

${ }^{5}$ See Chan-Lau and Morris (2004, 2005) for non-technical explanations of First-to-default and $\mathrm{N}^{\text {th }}$-to-default probabilities. 
that defaults among a number of institutions can be correlated. However, the major shortcoming of the FTD probability is its poor performance at capturing changes in the common component across institutions, as illustrated in Figure 4.

The FTD probability for the Korean corporate sector actually declines during the Asian crisis period. This result follows from the fact that a systemic crisis is the observable outcome of a common negative shock. Thus, for any time horizon considered, the likelihood of observing exactly one default among a number of institutions diminishes. Meanwhile, the probability of observing more than one default increases.

Figure 4. Korea: Expected Number of Defaults vs. Probability of Observing N-Defaults

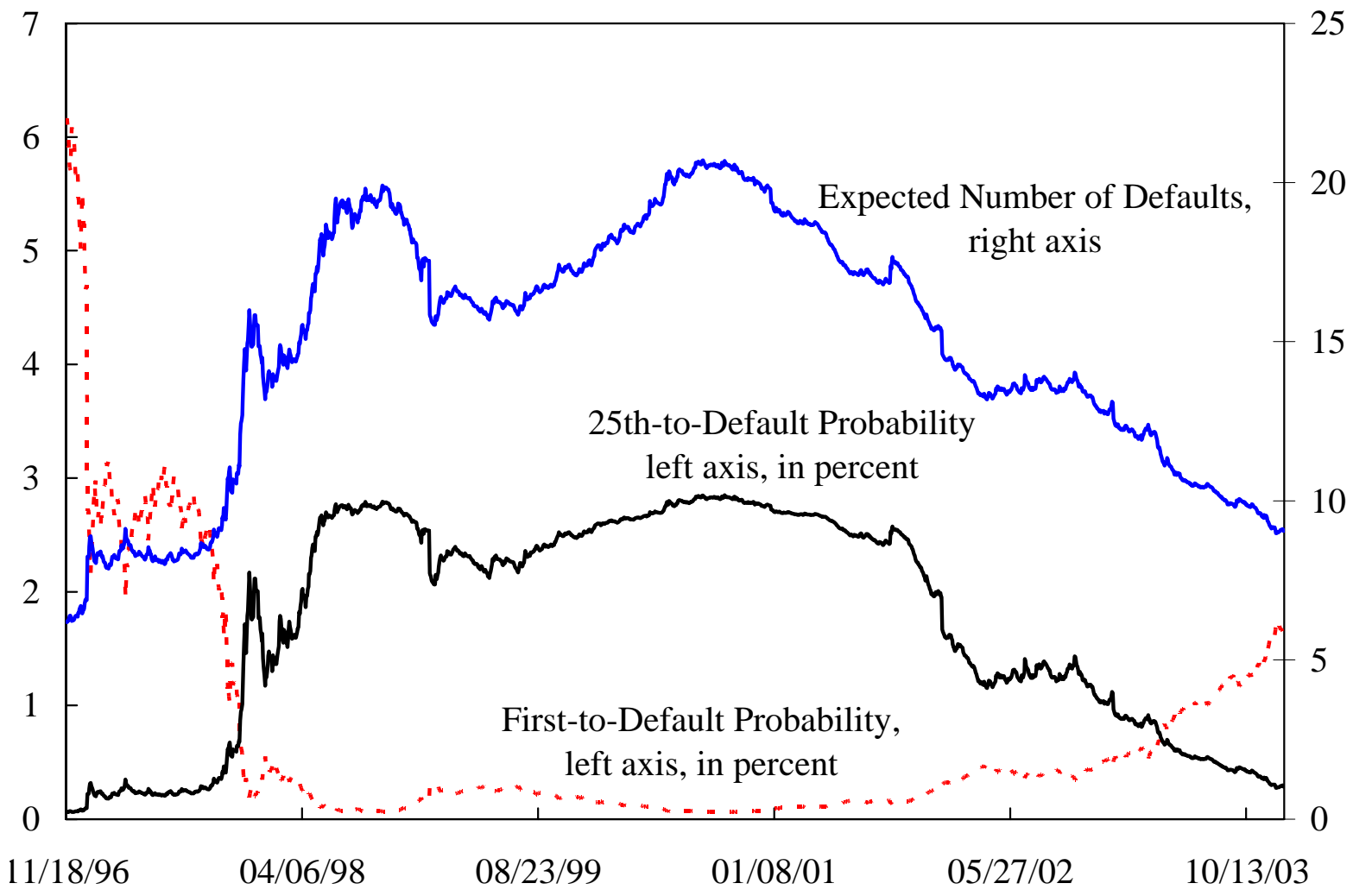

This phenomenon is illustrated by the widening of the probability distribution of default events in Korea both in November 1996 and September 1998 (Figure 5). As systemic risk increases, the probability of a larger number of default increases. In other words, the probability distribution becomes "fatter," a phenomenon that is captured by the increase in the expected number of defaults. Note also that in the case of Korea, the expected number of defaults is highly correlated with the probability of observing 25 defaults. It is tempting to conclude, then, that the $25^{\text {th }}$-to-default probability and END measure are equivalent. However, the choice of the adequate $\mathrm{N}^{\text {th }}$-to-default probability, however, would vary depending on the sector, country or region analyzed. 
Figure 5. Korea: Probability Distribution of N-Defaults

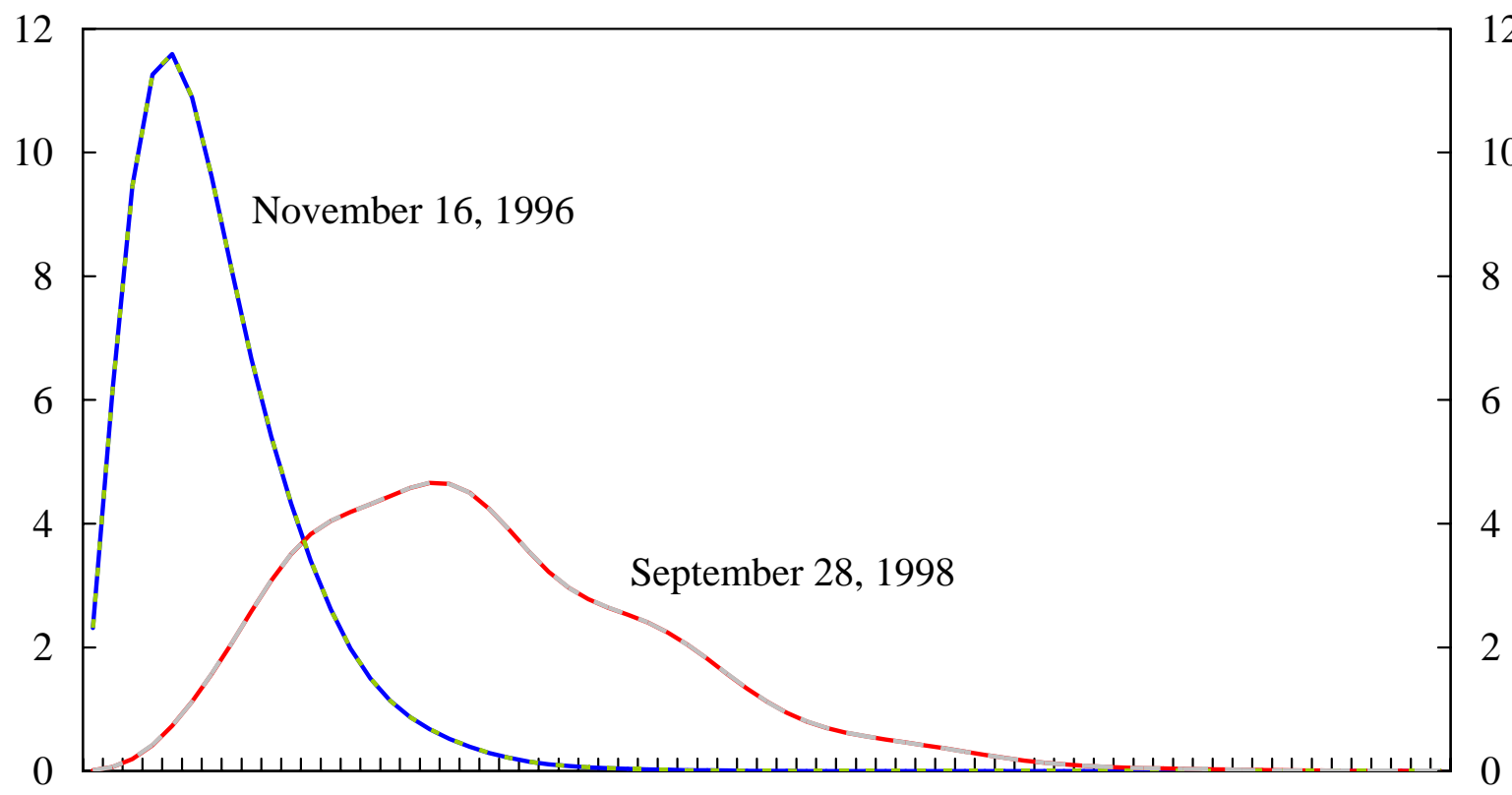

$\begin{array}{lllllllllllllllllllllll}1 & 4 & 7 & 10 & 13 & 16 & 19 & 22 & 25 & 28 & 31 & 34 & 37 & 40 & 43 & 46 & 49 & 52 & 55 & 58 & 61 & 64 & 67\end{array}$

Number of Defaults

\section{Contingent Claims Approach}

Contingent Claims Approach (CCA) is a very promising approach that integrates optionbased analysis along the lines of Merton (1974) within a macroeconomic framework (Gray, 2002). Therefore, the linkages between contingent liabilities in the corporate, banking, and government sectors are made explicit. The CCA delivers measures of credit spreads, distance-to-default, and default probabilities, and also computes their sensitivity to economic shocks, providing a useful stress-testing laboratory for policy makers. Because the modeling of contingent liabilities is based on Merton (1974) and risk measures at the banking and nonfinancial sectoral level are obtained using aggregate data, the same caveats discussed above apply. Also, some objections have been raised regarding the definition of liabilities in the model and the inability of the model to incorporate the willingness-to-pay factor. Nevertheless, we consider that an hybrid approach that integrates the contingent claims framework with our bottom-up approach to model systemic risk may yield useful tools for assessing sovereign risk.

\section{END: A BUILDING BLOCK FOR THE IMF’S SURVEILLANCE WORK}

For the reasons discussed in the preceding section, we suggest systemic risk is better captured by the END measure. The two-step approach used to construct the END measure makes use of the best price information available in the market: if credit default swap spread 
quotes and transaction data are available, individual default probabilities can be extracted directly from them rather than from equity price data. ${ }^{6}$

Going forward, the methodology proposed here to construct the END measure could be used to enhance the IMF's work on assessing risks and stress testing banking systems. The dynamics of the END measure are driven both by fundamental and technical factors. Once the dependence of the expected number of defaults on these factors is quantified and captured using an econometric model, as in Chan-Lau and Gravelle (2005b), it is straightforward to generate probability distribution of losses under different macroeconomic stress scenarios. This proposed extension of our methodology could help set the stress testing exercise on a solid foundation.

Finally, as discussed above, sovereign risk assessment could be improved by integrating this methodology into the contingent claims framework.

${ }^{6}$ Credit default swap spreads and equity prices may not convey the same information, though (Chan-Lau and Kim, 2004). 


\section{REFERENCES}

Chan-Lau, Jorge A., 2004, "Measuring Default Contagion in Emerging Markets,” Global Markets Monitor, October 28. , 2005, "Pricing Contagion: N-th to Default Credit Default Swaps,” Global Markets Monitor, January 24. , and Chris Morris, 2004, "First-to-Default Swaps,” Global Markets Monitor, November 18.

Chan-Lau, Jorge A., Arnaud Jobert, and Janet Kong, 2004, “An Option-Based Approach to Bank Vulnerabilities in Emerging Markets,” IMF Working Paper 04/33 (Washington, D.C.).

Chan-Lau, Jorge A., and Yoon Sook Kim, 2004, "Equity Prices, Credit Default Swaps, and Bond Spreads in Emerging Markets,” IMF Working Paper 04/27, forthcoming, ICFAI Journal of Derivatives Markets.

Chan-Lau, Jorge A., and Toni Gravelle, 2005a, “Measuring Systemic Risk,” in progress.

Chan-Lau, Jorge A., 2005b, “Macroeconomic Determinants of Systemic Risk,” in progress.

Gray, Dale, 2002, “Macro Finance: the Bigger Picture,” Risk, June.

Gropp, Reint, Jukka Vesala, and Giuseppe Vulpes, 2005, "Equity and Bond Market Signals as Leading Indicators of Bank Fragility,” forthcoming, Journal of Money Credit and Banking.

Haksar, Vikram, and Piyabha Kongsamut, 2003, “Dynamics of Corporate Performance in Thailand,” IMF Working Paper 03/214 (Washington: International Monetary Fund).

Hull, John, Mirela Predescu, and Alan White, 2004, “The Relationship between Credit Default Swap Spreads, Bond Yields, and Credit Ratings Announcements,” Journal of Banking and Finance 28, pp. 2789-2811.

International Monetary Fund, 2005, Global Financial Stability Report (Washington).

Mako, William, 2002, “Corporate Restructuring and Reform: Lessons from Korea” in Korean Crisis and Recovery, David Coe and Se-Jik Kim editors (Washington: International Monetary Fund).

Merton, Robert C., 1974, “On the Pricing of Corporate Debt: the Risk Structure of Interest Rates,” Journal of Finance 29, pp. 449-470. 
Pomerleano, Michael, 1999, “The East Asia Crisis and Corporate Finances: The Untold Micro Story,” World Bank Policy Research Working Paper No. 1990 (Washington, D.C.).

, Vikram Haksar, and Piyabha Kongsamut, 2003, "Dynamics of Corporate Performance in Thailand,” IMF Working Paper No. 03/214 (Washington: International Monetary Fund).

Tudela, Merxe and Garry Young, 2003, "Predicting default among UK companies: A Merton Approach,” Bank of England Financial Stability Review, June, pp. 104-114.

Vacisek, Oldrich, 1987, “Probability of Loss on Loan Portfolio,” unpublished. 